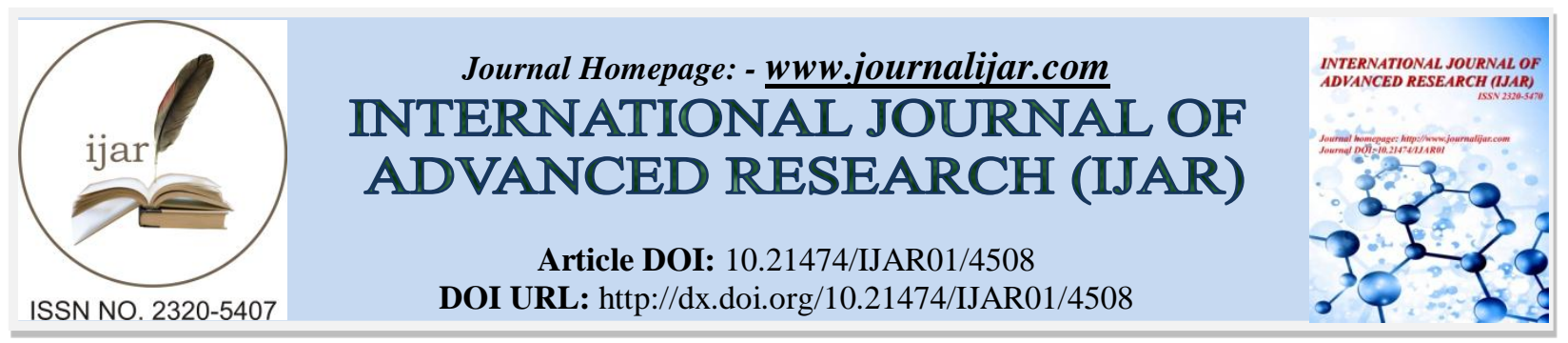

RESEARCH ARTICLE

\title{
APPLICATION OF NEURAL NETWORK TO PREDICT STRONG GROUND MOTION FOR HIMALAYAN REGION.
}

\author{
"Arjun Kumar ${ }^{1}$, Himanshu Mittal', Rajiv Sachdeva ${ }^{3}$ Rohtash Kumar ${ }^{4}$. \\ 1. Department of Civil Engineering, Arni University, Kathgarh, (H.P), India. \\ 2. \# 207, Back suit, Global Change Center National Taiwan University. \\ 3. Department of Earthquake Engineering, Indian Institute of Technology Roorkee-247667. \\ 4. Department of Geophysics, Banaras Hindu University Varanasi.
}

\section{Manuscript Info}

\section{Manuscript History}

Received: 17 April 2017

Final Accepted: 19 May 2017

Published: June 2017

Key words:-

neural, ground motion, regression,

Himalaya, India.

\section{Abstract}

To design engineering structures at a particular region, it requires the information about the characteristics of strong ground motion. Peak Ground Acceleration (PGA) is most frequently used parameter to characterize such ground motions. Ground motion predictions using regression analysis are commonly used for estimating these loading conditions by using strong ground motion data from previous recorded earthquakes. Artificial Neural Networks (ANNs) are efficient computing models which have shown their strengths in solving many complex problems in numerous fields. A data set of 398 strong ground motion records from 69 earthquakes $(3.0 \leq \mathrm{M} \leq 6.8)$ occurred in Himalayan region is used in this study. Multi-layer perceptron architecture with the error back-propagation learning algorithm has been adopted to estimate peak ground accelerations for the Himalayan earthquakes. The PGAs predicted by the ANN have been compared with PGAs obtained by regression analysis. From these observations it has been concluded that the perceptron model is quite promising for the estimation of peak ground acceleration. Results of the predicted PGA have indicated that ANN is a promising tool for the estimation of peak ground acceleration at a site.

Copy Right, IJAR, 2017,. All rights reserved.

\section{Introduction:-}

Strong Ground Motion (SGM) record at a particular site during an occurrence of earthquake is a result of complex non linear combination of many factors (Sachdeva, 2014). Ground motion associated with a peak ground acceleration of $0.05 \mathrm{~g}$ or higher is considered as strong ground motion (Chen and Scawthorn, 2003). For design of engineering structures for a specified region the information about the characteristics of strong ground motion is of paramount importance. Peak Ground Acceleration (PGA) is most frequently used parameter to characterize such ground motions. Ground Motion Prediction Equations (GMPE's) are commonly used for estimating these loading conditions by using strong ground motion data from previous recorded earthquakes. A very little agreement has been reached in the past 30 years of ground motion estimation relation studies and the scatter could not be reduced to requisite level. This is more because the relations not only depends upon data selection, characterization of source, path or site or the regression technique employed but also on the purpose for which equation is intended to be used. 
So the process of determining the regression relation much depends upon the appropriate judgment of scholar (Sachdeva, 2014).

Artificial Neural Networks (ANNs) are efficient computing models which have shown their strengths in solving many complex problems in numerous fields. They have the versatility to approximate a wide range of complex functional relationships between sets of input and output data. The purpose of this study is to predict strong ground motion parameters using ANN that are of primary significance in earthquake engineering. In this study, sets of Multilayer Perception (MLP) neural network model are trained to predict the PGA. Neuro Intelligence (Neural Network Simulator) software has been used to model ANN and the standard back-propagation supervised training scheme is used to train all networks. A data set of 398 strong ground motion records from 69 earthquakes $(3.0 \leq \mathrm{M} \leq 6.8)$ occurred in Himalayan region are used in this study. A comparision of PGA values obtained from neural network and regression analysis have made.

\section{Acceleration Data:-}

Two types of data sets collected from the Himalaya region have been used in the study. The first data set of 144 records from 10 earthquakes $(5.2 \leq \mathrm{M} \leq 6.8)$ as shown in Figure 1 became available from strong motion array comprised of strong motion accelerographs (SMA-1 of Kinematrics) in the Himalaya region. The purpose of deploy these instruments is to record the strong ground motion due to moderate and large-sized earthquakes occurring in the Himalayan region (Chandrasekharan, 1991). At each station the threshold level (trigger level) to sense the ground motion was set about $0.01 \mathrm{~g}$. The analog recordings of these earthquakes were manually digitized using a semi automatic digitizer and digital data was processed adopting standard processing procedures (Trifunac, 1976). The data was converted to a uniform sampling rate of 0.02 seconds and band-pass filtered $(0.17-0.20 \mathrm{~Hz} ; 25-27 \mathrm{~Hz})$ using an Ormsby filter (Chandrasekaran and Das, 1992).

The second data set of 254 records from 59 earthquakes of magnitude range $(3.0 \leq \mathrm{M} \leq 6.8)$ was recorded by recently installed digital accelerographs in the Himalayan region (Figure 2). These accelerograph installations form part of the National Strong Motion Network of 300 strong motion stations deployed under Mission Mode project to cover seismic zones V, IV and some thickly populated cities falling in seismic zone III (Kumar et al., 2012; Mittal et al., 2012). The digital accelerographs are of GSR-18 type (Geosig, model GSR-18) and data is acquired at a sampling rate of $200 \mathrm{~Hz}$. About 260 digital accelerographs, networked using NIC-net allows monitoring the health of accelerographs as well as downloading of the strong motion data at IIT Roorkee campus.

The earthquakes considered for training neural network are shown in Table 1. The magnitude distance distribution of these earthquakes is shown in Figure 4.

\section{Artificial Neural Network:-}

Artificial neural networks are among the most powerful learning models that are capable of establishing a mapping relationship between the given sets of inputs and outputs. The theoretical background on neural networks (NN) can be found in a large volume of literature (e.g., Zurada, 1992; Hagan et al., 1996; Bishop, 1995; Mehrotra et al., 1996; Haykin, 1994; Demuth et al., 2006; Arjun and Kumar, 2009).

In this study, multi-layer feedforward neural networks, commonly referred to as multilayer perceptrons (MLPs) have been used. It has a layered architecture consisting of input, hidden, and output layers. The input signal propagates through the network in a forward direction on a layer-by-layer basis. The output of each layer is transmitted to the input of neurons in the next layer through weighted links. The hidden layer aids in performing useful complex computations by extracting progressively more meaningful features from the input layer. Figure 3 shows a onehidden-layer MLP with D inputs, K hidden processing elements and M outputs (i.e., MLP (D-K-M)).

Training and weight adaptation is done in MLPs in a supervised manner with a highly popular algorithm known as the error back-propagation algorithm. Back-propagation learning consists of two phases. During the first phase, inputs presented to the input layer propagate through the network, layer by layer, to the output layer, where the error between the desired output and the network output is calculated. During this phase, the weights are not modified, and they remain constant. During the second phase, the error signal is propagated backwards from the output layer through the network to the input layer. During this stage, the weights are adjusted in such a way that the actual output moves closer to the desired output. 
Networks have been trained in this study by using the gradient descent with momentum learning scheme, which focuses on using the error between the network output and the desired output. The learning algorithm adapts the weights of the system based on the error until the system produces the desired output. The error criterion used is the $2 \mathrm{~L}$-norm or mean squared error (MSE) criterion. It simply computes the difference between the system output and the desired signal and squares it. The stopping criteria should be such that it addresses the problem of generalization. This has been done by stopping the training at the point of maximum generalization. The training set is usually divided into two sets: the training and the cross-validation sets. The training is stopped when the error in the crossvalidation set is smallest. This will be the point of maximum generalization.

\section{Application of ANN for estimating PGA:-}

A data set of 398 strong ground motion records from 69 earthquakes $(3.0 \leq \mathrm{M} \leq 6.8)$ occurred in Himalayan region is used in this study. Figure 4 gives the scatter plot of magnitude versus hypocentral distance of the data used. The neural network is trained and tested using the data.

The total set of 398 values has been divided into three sets:

1. training set,

2. validation set, and

3. testing set.

The training set, which is about $80 \%$ of the complete dataset, has been used to train the network; the validation set, which is about $10 \%$, has been used for the purpose of monitoring the training process, and to guard against overtraining; and the testing set, which is about $10 \%$, has been used to judge the performance of the trained network. The training was stopped when the cross-validation error began to increase, i.e., when the cross-validation error was minimum.

A [2-2-1] architecture with 9 weights have been selected which have 3.25 fitness. The training error is 0.35 ; validation error is 0.27 and testing error is 0.31 for this architecture. A correlation of 0.73 is obtained between the actual PGA and predicted PGA (Figure 5). Then estimated PGAs for magnitude 6.8 were compared with actual and that obtained from regression analysis.

$$
\log (A)=-1.497+0.3882 M-1.19\left(X+e^{0.2876 M}\right) \quad(\text { Kumar et al., 2017) }
$$

A good correlation has been observed between predicted by ANN and that obtained from regression analysis.

Table 1: The earthquakes considered for attenuation regression analysis:

\begin{tabular}{|l|l|l|c|c|l|l|l|}
\hline Earthquake & Date & Time & $\begin{array}{c}\text { Latitude } \\
\left({ }^{\circ} \mathbf{N}\right)\end{array}$ & $\begin{array}{c}\text { Longitude } \\
\left({ }^{\circ} \mathbf{E}\right)\end{array}$ & $\begin{array}{l}\text { Depth } \\
(\mathbf{K m})\end{array}$ & Magnitude & Records \\
\hline 1 & 19860426 & $13: 05$ & 32.18 & 76.29 & 07.0 & 5.5 & 9 \\
\hline 2 & 19860910 & $13: 20$ & 25.43 & 92.08 & 43.0 & 5.2 & 12 \\
\hline 3 & 19870518 & $07: 24$ & 25.27 & 94.20 & 50.0 & 5.7 & 14 \\
\hline 4 & 19880206 & $20: 21$ & 24.65 & 91.52 & 15.0 & 5.8 & 18 \\
\hline 5 & 19880806 & $06: 07$ & 25.15 & 95.13 & 91.0 & 6.8 & 33 \\
\hline 6 & 19900110 & $00: 21$ & 24.75 & 95.24 & 119.0 & 6.1 & 14 \\
\hline 7 & 19911020 & $02: 30$ & 30.74 & 78.79 & 12.0 & 6.6 & 13 \\
\hline 8 & 19950506 & $07: 29$ & 25.01 & 95.34 & 122.0 & 6.4 & 9 \\
\hline 9 & 19970805 & $08: 23$ & 24.89 & 92.25 & 35.0 & 5.6 & 11 \\
\hline 10 & 19990329 & $00: 35$ & 30.41 & 79.42 & 20.0 & 6.8 & 11 \\
\hline 11 & 20050406 & $08: 10$ & 31.20 & 91.10 & 10.0 & 4.3 & 1 \\
\hline 12 & 20051214 & $07: 09$ & 30.90 & 79.30 & 25.3 & 5.2 & 8 \\
\hline 13 & 20070722 & $23: 02$ & 31.20 & 78.20 & 33.0 & 5.0 & 2 \\
\hline 14 & 20080819 & $10: 54$ & 30.10 & 80.10 & 15.0 & 4.3 & 4 \\
\hline 15 & 20080904 & $12: 53$ & 30.10 & 80.40 & 10.0 & 5.1 & 7 \\
\hline 16 & 20090215 & $07: 35$ & 26.00 & 90.20 & 39.3 & 4.4 & 5 \\
\hline 17 & 20090224 & $17: 46$ & 25.90 & 94.30 & 10.0 & 4.8 & 5 \\
\hline 18 & 20090225 & $04: 04$ & 30.60 & 79.30 & 10.0 & 3.7 & 1 \\
\hline
\end{tabular}




\begin{tabular}{|c|c|c|c|c|c|c|c|}
\hline 19 & 20090318 & $11: 22$ & 30.20 & 78.90 & 10.0 & 3.3 & 1 \\
\hline 20 & 20090425 & 04:04 & 30.60 & 79.30 & 10.0 & 4.0 & 2 \\
\hline 21 & 20090501 & 10:11 & 30.20 & 78.10 & 10.0 & 4.6 & 7 \\
\hline 22 & 20090615 & $11: 17$ & 30.90 & 78.10 & 10.0 & 3.4 & 2 \\
\hline 23 & 20090615 & $12: 12$ & 27.40 & 79.20 & 05.0 & 3.0 & 1 \\
\hline 24 & 20090615 & 08:19 & 30.50 & 78.30 & 15.0 & 4.1 & 1 \\
\hline 25 & 20090819 & $10: 45$ & 26.60 & 92.50 & 20.0 & 4.9 & 2 \\
\hline 26 & 20090827 & $16: 54$ & 30.00 & 80.00 & 14.0 & 3.9 & 3 \\
\hline 27 & 20090830 & $19: 27$ & 25.40 & 94.80 & 85.0 & 5.3 & 5 \\
\hline 28 & 20090903 & $19: 51$ & 24.30 & 94.60 & 100.0 & 5.9 & 9 \\
\hline 29 & 20090921 & $08: 53$ & 27.30 & 91.50 & 08.0 & 6.2 & 14 \\
\hline 30 & 20090921 & $09: 43$ & 30.90 & 79.10 & 13.0 & 4.7 & 12 \\
\hline 31 & 20091003 & $05: 20$ & 30.00 & 79.90 & 15.0 & 4.3 & 3 \\
\hline 32 & 20091029 & $17: 00$ & 27.30 & 91.40 & 10.0 & 4.2 & 5 \\
\hline 33 & 20091029 & $19: 56$ & 26.60 & 90.00 & 05.0 & 5.2 & 5 \\
\hline 34 & 20091108 & $21: 43$ & 24.40 & 94.80 & 22.0 & 5.6 & 12 \\
\hline 35 & 20091229 & 09:01 & 24.50 & 94.80 & 80.0 & 5.5 & 6 \\
\hline 36 & 20091231 & $09: 57$ & 27.30 & 91.40 & 07.0 & 5.5 & 5 \\
\hline 37 & 20100111 & $05: 15$ & 29.70 & 80.00 & 15.0 & 3.9 & 3 \\
\hline 38 & 20100222 & $17: 23$ & 30.00 & 80.10 & 02.0 & 4.7 & 6 \\
\hline 39 & 20100226 & $04: 42$ & 28.50 & 86.70 & 28.0 & 5.4 & 7 \\
\hline 40 & 20100503 & $17: 15$ & 30.40 & 78.40 & 08.0 & 3.5 & 4 \\
\hline 41 & 20100531 & $11: 37$ & 30.00 & 79.80 & 10.0 & 3.6 & 2 \\
\hline 42 & 20100706 & 19:08 & 29.80 & 80.40 & 10.0 & 5.1 & 2 \\
\hline 43 & 20100710 & $03: 16$ & 29.90 & 79.60 & 10.0 & 4.1 & 4 \\
\hline 44 & 20100911 & $07: 02$ & 25.90 & 90.20 & 20.0 & 5.0 & 3 \\
\hline 45 & 20101212 & $01: 40$ & 25.00 & 93.30 & 15.0 & 4.8 & 2 \\
\hline 46 & 20110204 & $13: 53$ & 28.40 & 94.60 & 30.0 & 6.4 & 7 \\
\hline 47 & 20110209 & $11: 23$ & 27.45 & 92.24 & 10.0 & 5.0 & 6 \\
\hline 48 & 20110314 & 09:01 & 30.50 & 79.10 & 08.0 & 3.3 & 1 \\
\hline 49 & 20110404 & $11: 31$ & 29.60 & 80.80 & 10.0 & 5.7 & 22 \\
\hline 50 & 20110504 & 2057 & 30.20 & 80.40 & 10.0 & 5.0 & 1 \\
\hline 51 & 20110620 & $06: 27$ & 30.50 & 79.40 & 12.0 & 4.6 & 13 \\
\hline 52 & 20110623 & $22: 13$ & 30.00 & 80.50 & 05.0 & 3.2 & 1 \\
\hline 53 & 20110918 & $12: 40$ & 27.70 & 88.20 & 10.0 & 6.8 & 13 \\
\hline 54 & 20110921 & $02: 24$ & 30.90 & 78.30 & 10.0 & 3.1 & 1 \\
\hline 55 & 20110924 & $14: 32$ & 30.90 & 78.30 & 10.0 & 3.0 & 1 \\
\hline 56 & 20120116 & 05:01 & 29.70 & 78.90 & 10.0 & 3.6 & 1 \\
\hline 57 & 20120226 & $23: 08$ & 29.60 & 80.80 & 10.0 & 4.3 & 2 \\
\hline 58 & 20120510 & 22:00 & 30.20 & 79.40 & 05.0 & 3.9 & 1 \\
\hline 59 & 20120728 & $05: 48$ & 29.70 & 80.70 & 10.0 & 4.5 & 2 \\
\hline 60 & 20120823 & $16: 30$ & 28.40 & 82.70 & 10.0 & 5.0 & 3 \\
\hline 61 & 20121111 & $18: 39$ & 29.20 & 81.50 & 10.0 & 5.0 & 3 \\
\hline 62 & 20121127 & 12.15 & 30.90 & 78.40 & 12.0 & 4.8 & 4 \\
\hline 63 & 20130102 & $17: 42$ & 29.40 & 81.10 & 10.0 & 4.8 & 2 \\
\hline 64 & 20130109 & $07: 44$ & 29.70 & 81.70 & 34.0 & 5.0 & 4 \\
\hline 65 & 20130110 & $15: 16$ & 30.10 & 80.40 & 05.0 & 3.2 & 1 \\
\hline 66 & 20130129 & $19: 42$ & 30.00 & 81.60 & 07.0 & 4.0 & 1 \\
\hline 67 & 20130211 & $10: 48$ & 30.00 & 78.40 & 05.0 & 4.3 & 3 \\
\hline 68 & 20130217 & $16: 27$ & 30.90 & 78.40 & 10.0 & 3.2 & 1 \\
\hline 69 & 20130905 & $18: 35$ & 30.90 & 78.50 & 11.0 & 3.5 & 1 \\
\hline
\end{tabular}




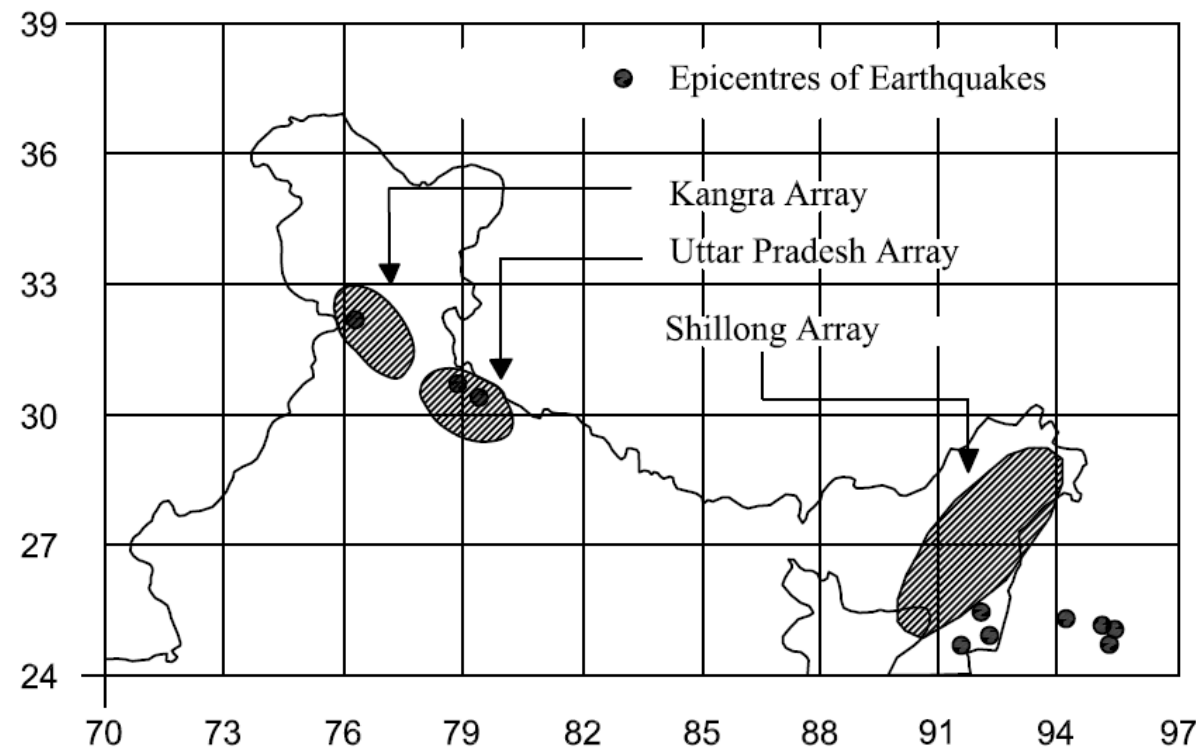

Figure 1:-. Map showing the strong motion arrays and locations of earthquakes (Sharma, 2005).

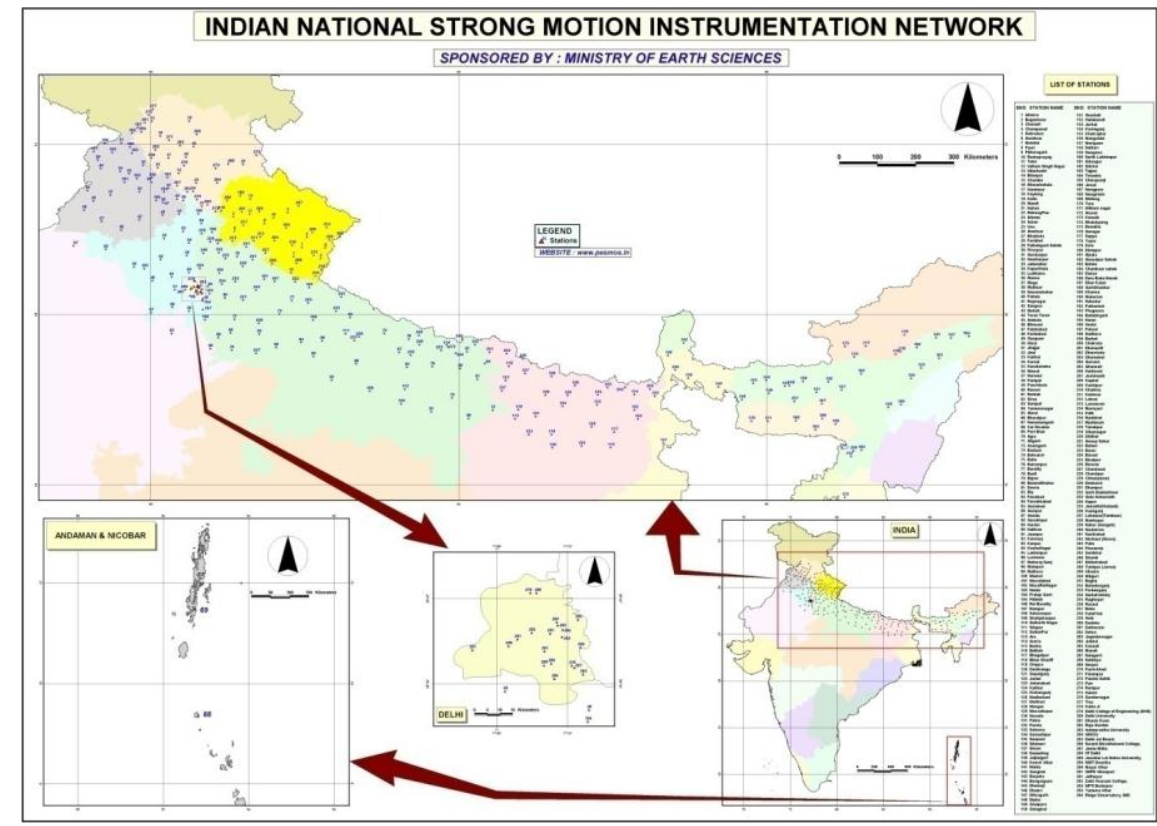

Figure 2:- Indian nation strong motion instrumentation network (Kumar et al., 2012).

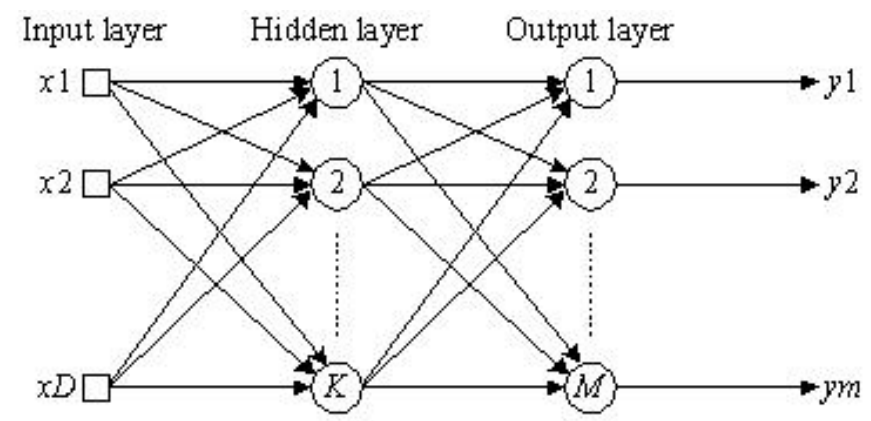

Figure 3:- Multilayer perceptron, MLP $(D-K-M)$, with one hidden layer. 


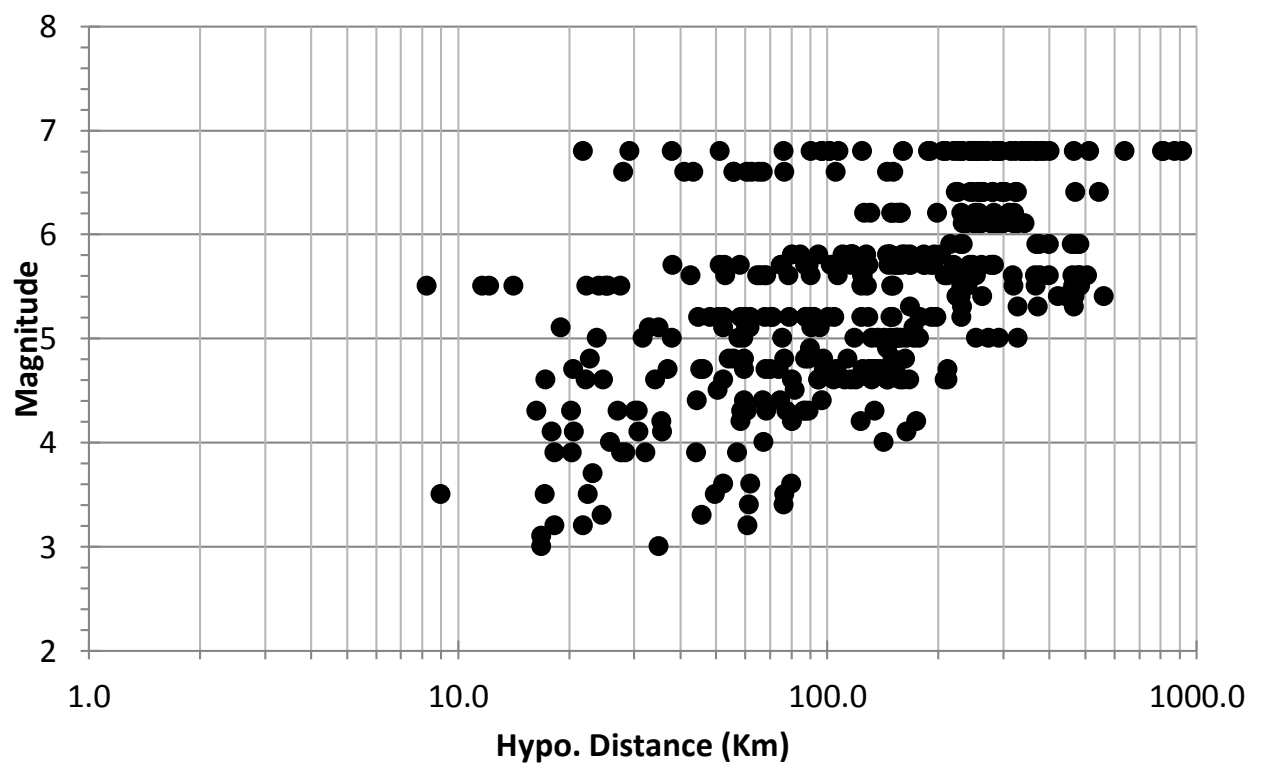

Figure 4:- The magnitude-distance distribution of peak ground horizontal accelerations.

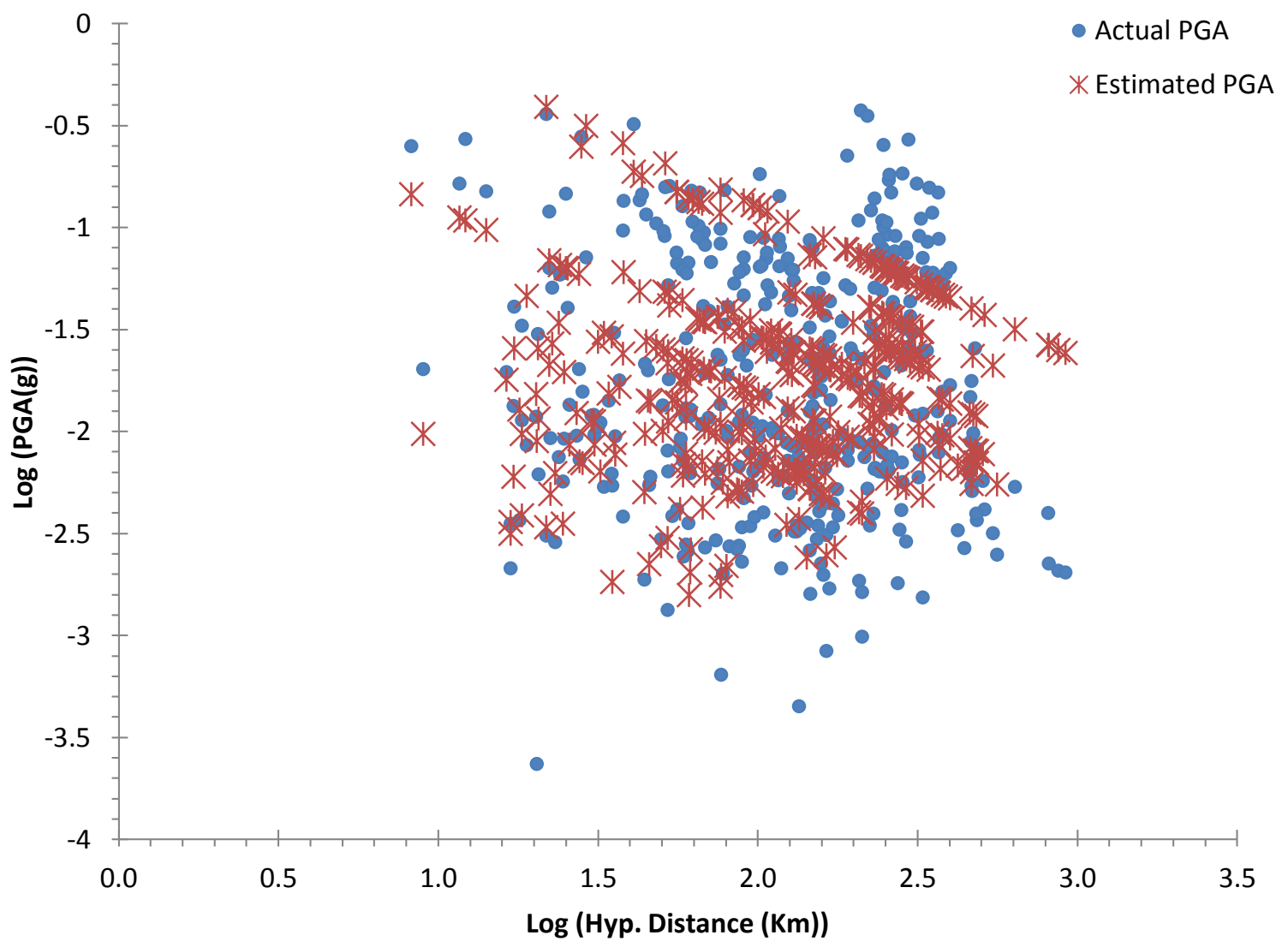

Figure 5:- Scatter plot showing actual PGA vs estimated PGA. 


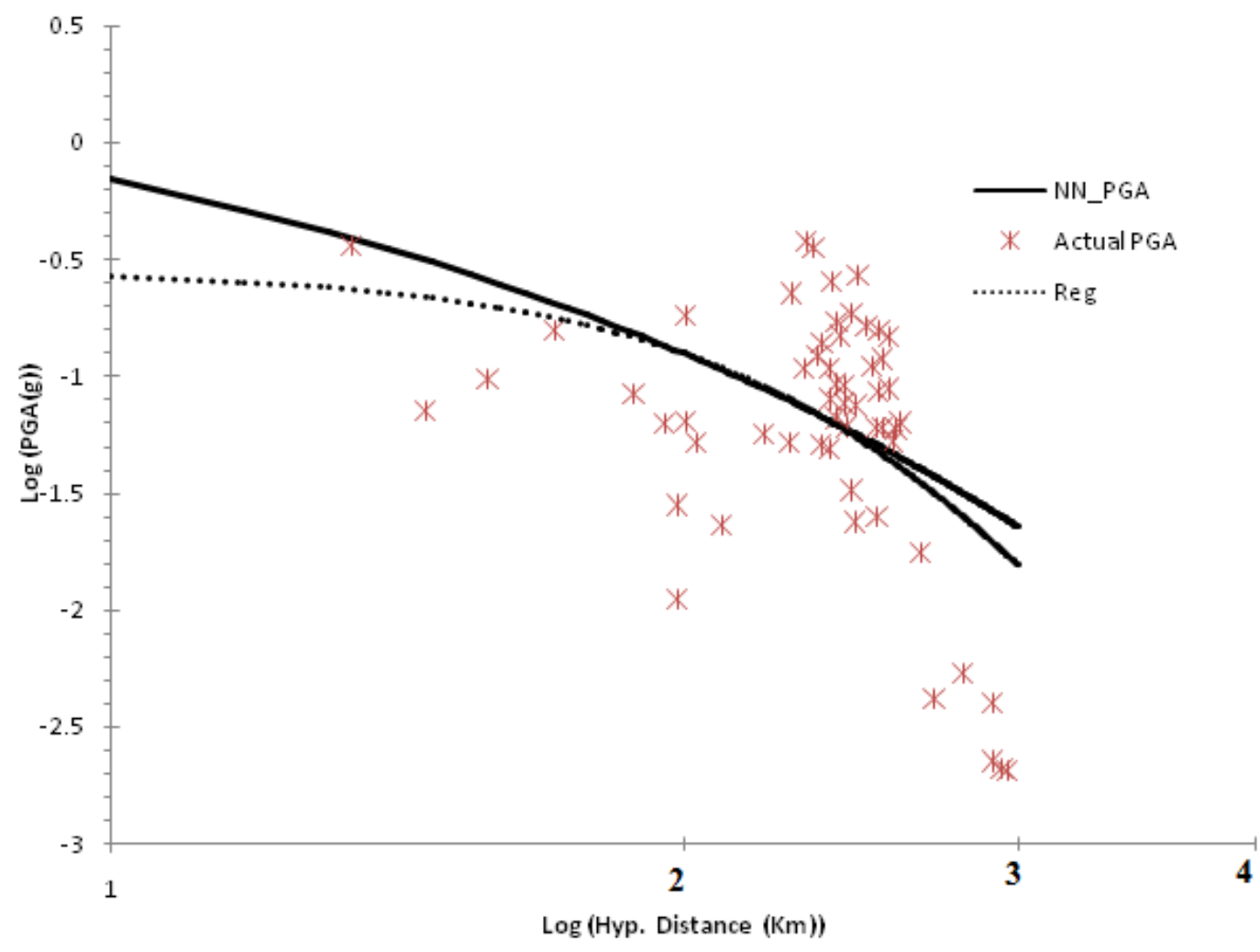

Figure 6:- Plot shows actual PGA; estimated by ANN and regression analysis.

\section{Conclusions:-}

A multi-layer perceptron architecture with the error back-propagation learning algorithm has been adopted to estimate peak ground accelerations for the Himalayan earthquakes. The PGAs predicted by the ANN have been compared with PGAs obtained by regression analysis. From these observations it has been concluded that the perceptron model is quite promising for the estimation of peak ground acceleration. Results of the predicted PGA have indicated that ANN is a promising tool for the estimation of peak ground acceleration at a site. The performance of networks may be improved by carrying a detailed parametric study on the optimal network to be used for predicting the peak ground acceleration. Future work may also examine the application of hybrid artificial intelligence techniques.

\section{Acknowledgments:-}

The authors are thankful for the first data set of strong-motion provided by the research scheme "Strong Motion Arrays in India," sponsored by the Department of Science and Technology, Government of India. The authors are also thankful to Ministry of Earth Sciences (MoES) for funding the project under which the second data was collected. The author sincerely thanks Prof. Ashok Kumar and Prof. Ashwani Kumar for their helpful suggestions, advice, and critical comments at various stages of the study.

\section{References:-}

1. Arjun CR and Kumar A (2009) Artificial Neural Network-Based estimation of peak ground acceleration. ISET Journal of Earthquake Technology 46 (1):19-28.

2. Bishop CM (1995) Neural Networks for Pattern Recognition, Oxford University Press, Oxford, U.K.

3. Borkar Y, Kumar A, Gupta SC and Kumar A (2013). Source Parameters and Scaling Relation for local earthquakes in the Garhwal and Kumaon Himalaya, India. International Journal of Advanced Seismology, 1(1), $1-15$.

4. Chandrasekaran AR and Das JD (1991) Analysis of strong ground motion accelerograms of Uttarkashi Earthquake of October 20. Department of Earthquake Engineering, University of Roorkee, India. Report EQ 9110. 
5. Chandrasekaran AR and Das JD (1992) Strong motion arrays in India and analysis of data from Shillong array. Curr Sci 62:233-250.

6. Chen WF and Scawthorn C (2003) Earthquake Engineering Handbook. NewYork, U.S.A: CRC Press.

7. Demuth H, Beale M and Hagan M (2006) Neural Network Toolbox 5: User's Guide, The MathWorks, Inc., Natick, U.S.A.

8. Hagan MT, Demuth HB and Beale M (1996) Neural Network Design, PWS Publishing Company, Boston, U.S.A.

9. Haykin S (1994) Neural Networks: A Comprehensive Foundation. Prentice-Hall, Inc., New Jersey, U.S.A.

10. Kumar A, Gupta SC, Kumar A, Sen A, Jindal AK and Jain S (2006). Estimation of source parameters from local earthquakes in western part of the Arunachal Lesser Himalaya. 13th Symposium on Earthquake Engineering, 9-17.

11. Kumar A, Mittal H, Sachdeva R, Kumar A (2012) Indian strong motion instrumentation network. Seism Res Lett 83(1):59-66.

12. Kumar A, Kumar A, Kumar A, Mittal H and Bhardwaj R (2012). Software to Estimate Spectral and Source Parameters. International Journal of Geosciences, 3(5), 1142-1149.

13. Kumar A, Kumar A and Mittal H (2013). Earthquake Source Parameters - A Review in Indian Context. International Journal of Civil, Structural, Environmental and Infrastructure Engineering Research and Development, 3(1), 41-52.

14. Kumar A, Kumar A, Gupta SC, Mittal H and Kumar R (2013). Source Parameters and $f_{\max }$ in Kameng Region of Arunachal Lesser Himalaya. Journal of Asian Earth Sciences, 70-71, 35-44.

15. Kumar A, Kumar A, Gupta SC, Mittal H and Sen A (2014). Earthquake Source Parameters of Local Earthquakes and their scaling in the Uttarakhand region of NW Himalaya. Disaster Advances 7(9), 28-41.

16. Kumar A, Kumar A, Gupta SC, Jindal AK and Ghangas V (2014). Source Parameters of Local Earthquakes in Bilaspur Region of Himachal Lesser Himalaya. Arabian Journal of Geosciences 7(6), 2257-2267.

17. Kumar A, Mittal H, Kumar R and Ghangas V (2014).High frequency cut-off of observed earthquake spectrum and source parameters of local earthquakes in Himachal Himalaya. International Journal of Science and Research, 3(7), 1642-1651.

18. Kumar A, Kumar R, Ghangas V and Sharma B (2015). MATLAB codes (CodaQ) for estimation of attenuation characteristics of coda waves. International Journal of Advanced Research, 3(9), 1078-1083.

19. Kumar A, Mittal H, Kumar R and Ahluwalia RS (2017). Empirical Attenuation relationship for Peak Ground Horizontal Acceleration for North-East Himalaya. Vietnam Journal of Earth Sciences, 39(1), 46-56.

20. Kumar R, Gupta SC and Kumar A (2014). Attenuation characteristics of seismic body waves for the crust of Lower Siang region of Arunachal Himalaya.International Journal of Advanced Research, 2(6), 742-755.

21. Mehrotra K, Mohan CK and Ranka S (1996) Elements of Artificial Neural Networks. Penram International Publishing (India) Pvt. Ltd., Mumbai.

22. Mittal H, Kumar A and Ramhmachhuani R (2012) Indian National Strong Motion Instrumentation Network and Site Characterization of Its Stations. Int J Geosci 3(6):1151-1167.

23. Mittal H, Kumar A and Kumar A (2013). Site effects estimation in Delhi from Indian Strong Motion network. Seismological Research Letters, 84(1), 33-41.

24. Mittal H, Kumar A, Kumar A and Kumar R (2014). Analysis of Ground Motion in Delhi from Earthquakes recorded by Strong Motion Network. Arabian Journal of Geosciences.DOI 10.1007/s12517-013-1223-8.

25. Sachdeva R (2014) Application of ANN in strong motion prediction. A Ph.D thesis submitted to IIT Roorkee.

26. Sen A, Kumar A, Gupta SC and Kumar A (2014). Spectral analysis of the earthquake sources around Roorkee (INDIA) region and its surrounding Indo-Gangetic planes.Disaster Advances 7(6), 1-11.

27. Sharma K, Bala R, Kumar A and Kumar R (2016). Matlab codes (Qbody) to study attenuation of seismic bodywaves. International Journal of Advanced Research, 4(1), 107-117.

28. Sharma S, Kumar A and Ghangas V (2013). Seismicity in Jammu and Kashmir Region with Special Reference to Kishtwar. International Journal of Scientific and Research Publications 3(9), 1-5.

29. Trifunac MD (1976) Preliminary analysis of the peaks of strong earthquake ground motion - dependence of peaks on earthquake magnitude, epicentral distance, and recording site conditions. Bull Seismol Soc Am 66 (1), 189-219.

30. Zurada JM (1992) Introduction to Artificial Neural Systems, West Publishing Company, USA. 